\title{
Fast reactor delays lead to plutonium cutbacks in Japan
}

Tokyo. Japan is expected to announce on Friday (24 June) plans to cut back on the production of plutonium from recycled nuclear fuel, as part of a long-awaited revision by the Atomic Energy Commission (AEC) of the country's nuclear energy policy.

The revised plans for plutonium are in part a response to growing international concerns about proliferation, and in particular to rising tensions over North Korea's suspected diversion of plutonium to the manufacture of nuclear weapons.

But the main reasons for reducing plutonium production are unrelated delays in the development of fast breeder reactors, and in the construction of facilities for the reprocessing of spent nuclear fuel within Japan.

The AEC's long-term plans, which were last revised in 1987, cover all aspects of nuclear power policy. But worldwide attention has focused in particular on plutonium. Under the existing policy, the AEC had estimated that, as a result of reprocessing fuel both within Japan and overseas, the country's supply of plutonium would rise dramatically from its current level of about 2 tonnes to 80 to 90 tonnes by 2010 .

This figure far exceeds Japan's needs for its fast breeder programme, and has stimulated severe international criticism of the country's plutonium policy. Indeed, despite strong denials from the government, it has led some critics to suggest that Japan may be tempted to divert plutonium to the manufacture of nuclear weapons.

Under the revised policy, the supply of plutonium by 2010 will fall to 69 to 79 tonnes. The main reason for the reduction is that initial operations of Japan's first commercial fuel reprocessing plant, in Rokkasho in northern Japan, will be put back from 1998 to early in the next decade.

The AEC has also postponed plans for a second commercial reprocessing plant, previously due to begin operation in 2010 . Instead, a decision on when to build the plant will now be made around 2010 .

Government officials acknowledge that the revised policy has been influenced even if only indirectly - by international concern over proliferation of nuclear weapons. A report on nuclear energy policy, released on 10 June by an advisory committee of the Ministry of International Trade and Industry, specifically mentions suspicion of nuclear weapon development in North Korea as a factor that has required Japan to revise its nuclear fuel cycle policy.

Two factors combine to reduce plutonium demand early in the next century.
First, Japan's failure to meet its targets for development of fast breeder reactors. Initial operation of Japan's prototype fast breeder reactor, Monju, was delayed 18 months because of technical difficulties.

Second, the electric power industry has decided to postpone building of a demonstration fast breeder reactor by several years until around 2005.

Even the new figures mean that Japan will have far more plutonium on its hands than it needs for its fast breeder programme. According to supply and demand figures in the AEC report, more than half of the plutonium produced in the period 2000 to 2010 is

\section{IMAGE UNAVAILABLE FOR COPYRIGHT REASONS}

\section{Public protests have been spectacular.}

earmarked for use in ordinary light water reactors, and in a yet-to-be-built advanced thermal reactor, by mixing it with uranium.

Another factor is that commercial fast breeder reactors are not now expected to come on-line until at least 2030 , rather than between 2020 and 2030 , as predicted in the AEC's old policy.

The AEC report also calls for research and development on a new form of fuel reprocessing incorporating into plutonium fuel highly radioactive transuranic elements that are normally discarded as high-level waste (see Nature 359, 766; 1992).

This approach has the advantage of providing a way of burning up high-level waste, and also makes it more difficult to divert the plutonium to the manufacture of nuclear weapons. But there are many technical hurdles to overcome, as its much higher radioactivity means that the fuel is much harder to handle, requiring advanced robot technology.

Despite these difficulties, Japan's Science and Technology Agency, which funds the country's nuclear energy $R \& D$, is determined to press ahead with the new technique. It plans to seek R\&D funds for this purpose in its budget request for next year, due to be submitted at the end of August. The AEC report also calls for construction of a test reactor designed to experiment with this modified form of plutonium fuel.

David Swinbanks

\section{Computer networks break new ground in agency cooperation}

Tokyo. The many computer networks belonging to the various science-related government ministries and agencies in Japan seem finally to be on the verge of being merged into a comparatively seamless whole.

On Monday (20 June), Japan's prime minister Tsutomu Hata called on all government bodies to cooperate in the development of computer networks. He was responding to a report prepared by a committee of the Council of Science and Technology, Japan's leading science policymaking body, which Hata heads.

The report, entitled How to advance presentresearch information networks: promotion of applications, makes repeated calls for the establishment of a "seamless" system of government computer networks.

At present, each science-related ministry and agency runs its own networks and there is very little flow of information between them. The Ministry of Education, Science and Culture, for example, runs the computer networks linking Japan's universities. Various other ministries and agencies, such as the Agency of Industrial Science and Technology, the Science and Technology Agency, the Ministry of Posts and Telecommunications, the Ministry of Agriculture, Forestry and Fisheries, and the Ministry of Health and Welfare have networks for their own researchers.

This autumn, a new inter-ministry research network will be established with gateway nodes in Tokyo, Tsukuba science city, and Osaka. This will allow full transfer of information, including electronic mail, file transfer protocol, and access to databases, between the various government networks. The new network will have a high-capacity link, operating at 2 megabits per second, with the National Science Foundation network in the United States. Links to Europe and Asia are planned for next year.

Tateo Arimoto, the director of the Science and Technology Agency's science and technology information division, says the various ministries and agencies are about to reach agreement on acceptable uses of the new network

The network will be available for "research purposes" only. But private companies will be able to gain limited access if they have cooperative research agreements with government research organizations.

In another first for Japan, the government report on computer networks will be released on the Internet in both Japanese and English versions. It can be accessed by anonymous file transfer protocol through the Japan Information Centre of Science and Technology (ftp.jicst.go.jp).

David Swinbanks 